\title{
Building a New Eco-System to Transform a Smarter Logistics Industry with Smarter Logistics Cloud
}

\author{
Lei Qin \\ Cloud Labs, Smarter Commerce Lab. Based Service, IBM CGC, China \\ qinlei@cn.ibm.com
}

\begin{abstract}
China is well known as a "World Factory", where logistics is one of the key service industries. The market of logistics in China is huge. The logistics cost is over $18 \%$ of Chinese GDP, and it is rapidly growing at $14 \%$ increasing rate yearly. However, the logistics industry in China is inefficient and fragmentary. The rate of total logistics cost of entire GDP is even twice times bigger than developed countries. IBM is now working with the Chinese Government and local business partners to deliver a "Smarter Logistics Cloud" by applying IBM technologies such as Smarter Commerce, Cloud, Business Optimization, Business Analytics, Mobile technologies etc. Ningbo is one of the largest ports in China. We will implement in market innovation and start the transformation of service industry from Ningbo, roll it out it China, and eventually spread out to other emerging countries.
\end{abstract}

Keywords: smarter logistics, cloud computing, industry transformation, Ningbo logistics.

\section{Brief Biography}

Lei (Larry) Qin joined the IBM Software Group in 1997. During the period 1997 to 2004, Mr. Qin served the IBM Software Group as IT engineer and senior IT expert respectively, and in these capacities he had a leading role in projects concerning Lotus groupware, Internet security, and enterprise content management in various areas of design and implementation of a series of success stories including Industrial and Commercial Bank of China, people's Bank of China, Bank of China, Beijing Mobile, and China Life Insurance.

From 2004 to 2007, Mr. Qin served as Technical Sales Manager of the IBM Software Group being responsible for the Tivoli line of products in China, technical sales, and support and promotion work. In the beginning of 2008, Mr. Qin became software architect and technical director of IBM's Software Group, leading the software division team for a number of industrial customers including government, business, manufacturing, distribution, transportation, retail, software architecture design, and software and industry solutions. In 2009, Mr. Qin also served as vice president of the IBM China Development Center.

The original version of this chapter was revised: The copyright line was incorrect. This has been corrected. The Erratum to this chapter is available at DOI: 10.1007/978-3-642-33068-1_20

M. van Sinderen et al. (Eds.): IWEI 2012, LNBIP 122, pp. 3-4 2012.

(C) IFIP International Federation for Information Processing 2012 
From the end of 2009, Mr. Qin served as general manager of the Greater China Group (GCG) cloud computing laboratory and high-performance solutions within the IBM China Development Center.

Since 2012, Mr. Qin is also e-commerce director of laboratory services of the IBM China Development Center GCG, and serves as the Ningbo smart logistics cloud project director. 